\title{
Comparison of Light-Colored Soy Sauce (Usukuchi) with Regular Soy Sauce (Koikuchi) on Rheological Properties of Various Boiled Vegetables
}

\author{
Tomoko Maeda, ${ }^{1}$ Tatsuo Murata, ${ }^{2}$ Michiyo WATANABE ${ }^{3}$ and Naofumi Morita ${ }^{3 *}$ \\ ${ }^{1}$ Department of Life and Health Sciences, Hyogo University of Teacher Education, 942-1 Shimokume, Yashiro, Hyogo 673-1494, Japan \\ ${ }^{2}$ Higashimaru Shoyu Co., Ltd., 100-3 Tominaga, Tatsunosho, Tatsuno, Hyogo 679-4193, Japan \\ ${ }^{3}$ Lab. of Food Chemistry, Graduate School of Agriculture and Biological Sciences, Osaka Prefecture University, 1-1 Gakuencho, Sakai, Osaka \\ 599-8531, Japan
}

Received July 10, 2003; Accepted October 16, 2003

\begin{abstract}
Effects of light-colored (Usukuchi) and regular soy sauces (Koikuchi) on rheological properties of boiled foods were determined using a rheometer. The amounts of soy sauces were added to the ingredients with the same levels as those providing the highest and best scores for the sensory test. A taro corm, potato tuber, pumpkin fruit, Japanese radish root and carrot root were boiled according to a recipe in an electric cooker. Firmness of taro, potato and Japanese radish boiled with Usukuchi was significantly softer than that boiled with Koikuchi. The cooking time of taro with Koikuchi was longer than that with Usukuchi, but the tissue of taro boiled with Usukuchi was still softer. In a boiling test at the same $\mathrm{NaCl}$ concentration of $2.0 \%(\mathrm{w} / \mathrm{w})$, the firmness of boiled potato decreased in order of $\mathrm{NaCl}$ alone solution, Usukuchi and Koikuchi solutions. Therefore, the taste or food texture of food boiled in Usukuchi might be due to the cooking property of this sauce, which softened the firmness of the boiled food as compared with that of Koikuchi. The cooking property of Usukuchi might be influenced by its higher concentration of $\mathrm{NaCl}$, and also the co-existence of organic acids, amino acids and browning products.
\end{abstract}

Keywords: soy sauce, rheological property, firmness, boiled food

Soy sauce is a good seasoning that can be used with almost every Japanese dish in various ways, such as boiling, broiling, frying, grilling and dipping. It is also used as salad dressing, a soup base and for pickling vegetables. Soy sauce improves many kinds of taste and flavor as a result of its own distinct taste aroma and color (Ueda, 1977). It provides a salty taste and special preferred aroma and also a few drops of soy sauce are often used as what the Japanese call "subtle seasoning." Soy sauce contains about $18 \%(\mathrm{w} / \mathrm{w})$ sodium chloride $(\mathrm{NaCl})$, but when a little is poured out and tasted, we cannot recognize the real saltiness, because of the main action of amino acids that make the saltiness mild to the tongue. Boiling with soy sauce is an essential cooking method to produce umami derived from amino acids in Japanese cuisine.

Two kinds of soy sauce, namely light-colored (Usukuchi) and regular (Koikuchi), are commonly used depending on the kind of cooking. In general, Koikuchi is used for cooking fish because it has an effect of masking the unpleasant smell, whereas Usukuchi is used for vegetables to retain the original color. Especially in the Kansai district of Japan, Usukuchi is preferred for use in various kinds of cooking because many people want to enjoy the natural taste in their cuisine. Japanese people highly value the natural coloring, shape, taste and aroma of foods, preferring to maintain as much as possible the natural food and food texture and feeling of the original ingredients.

\footnotetext{
* To whom correspondence should be addressed.
}

E-mail: morita@biochem.osakafu-u.ac.jp
Changes in food texture of carrot during cooking have been studied using a physicochemical method (Belie et al., 2002). However, there are few studies on the relations between the firmness of cooked vegetables and amount of $\mathrm{NaCl}$ in Koikuchi or Usukuchi, as they relate to the delicious or juicy food texture of the cooked ingredients. As to cooking methods or recipes using soy sauces for various boiled foodstuffs in Japanese cuisine, Usukuchi and Koikuchi have been used for boiling of some foods under different cooking conditions, and a sensory evaluation of both soy sauces was reported. Usukuchi obtained higher scores than Koikuchi in the sensory test, as reported previously (Tomioka et al., 2002; Okuda et al., 2002a; Ikeuchi et al., 2002a; Okuda et al., 2002b and Ikeuchi et al., 2002b), and the Usukuchi was reported to be more favorable for boiled foods. In the present study, Usukuchi and Koikuchi were used to determine the rheological properties of various boiled foods using the same cooking model and these differences were discussed from the results of a sensory test as proposed previously.

\section{Materials and Methods}

Materials for cooking by boiling Taro corm, potato tuber, pumpkin fruit, Japanese radish root and carrot root were obtained from a local market in Sakai (Osaka, Japan). All materials were harvested in Japan except for the taro corm, which was imported from China as frozen-corm (called 'taro'). Usukuchi, Koikuchi and seasoning soup were products of Higashimaru Co., Ltd. (Hyogo, Japan) and used in the following boiling preparation. Characteristics of these materials are shown in Table 1. Other 
chemicals and materials were analytical or food grade.

Methods of boiling Tools for boiling were the same as reported previously (Tomioka et al., 2002; Okuda et al., 2002a; Ikeuchi et al., 2002a; Okuda et al., 2002b; Ikeuchi et al., 2002b). A domestic electric cooker (model KZ-p8, $100 \mathrm{~V} \mathrm{IH,} \mathrm{Matsushita}$ Co., Ltd., Osaka) was used and boiling temperature was controlled by the unit's switches at 7 stages from $0.075 \mathrm{~kW}$ to 1.4 $\mathrm{kW}$. A pan constructed with three-layer structure (inside, 0.45 $\mathrm{mm}$; center, $1.0 \mathrm{~mm}$; outside, $0.55 \mathrm{~mm}$ thickness) (Yoshikawa Co., Ltd., Niigata) was also used. The materials of the three layers were as follows: inside, SUS 304L (stainless steel, $18 \% \mathrm{Cr}$, $10 \% \mathrm{Ni}$ ); center, pure aluminum; outside, NAR-160 (steel containing $16.75 \% \mathrm{Cr}, 0.38 \% \mathrm{Cu}$ and $0.52 \% \mathrm{Nb}$ ). A lid with a $16 \mathrm{~cm}$ diameter for the pan was made of aluminum and had 8 holes $(\phi$ $10 \mathrm{~mm})$.

According to the cooking recipe, boiling was performed using the same method as reported previously (Tomioka et al., 2002; Okuda et al., 2002a; Ikeuchi et al., 2002a; Okuda et al., 2002b; Ikeuchi et al., 2002b). In this study, soy sauces and seasonings were added to the ingredients in the same amounts that provided the highest and best scores for the sensory test (Tomioka et al., 2002; Okuda et al., 2002a; Ikeuchi et al., 2002a; Okuda et al., 2002b; Ikeuchi et al., 2002b). Soy sauce concentrations used for the sensory test were as follows: taro corm, 6, 12, 18, 24 and $30 \%$; potato tuber, 3.6, 4.8, 6.0, 7.2, 8.4 and 9.6\%; pumpkin fruit, 3.0, 4.5, 6.0 and 7.5\%; Japanese radish root, 4, 6, 8, 10, 12 and $14 \%$; carrot root, 12, 24, 36 and $48 \%$ of the material weight. The recommended concentrations of Usukuchi and Koikuchi providing the best taste of the boiled food ingredients are shown in Table 2.

In addition, cooking ingredients were listed using the most suitable concentration of the soy sauces (Table 3 ). The materials for potato tuber, Japanese radish root and carrot root were cooked with other ingredients according to ordinary boiling. Original concentrated seasoning soup was diluted 15 times with distilled water and used for some of the cooking, as shown in Table 3. Japanese sake (gousei-seishu, alcohol concentration of $13-14 \%(v / v))$ was purchased from a liquor shop. All boiling

Table 1. Characteristics of soy sauces and seasoning soup used for boiling.

\begin{tabular}{|c|c|c|c|c|c|c|c|c|c|}
\hline \multirow{2}{*}{ Ingredients } & Energy & $\mathrm{NaCl}^{a)}$ & Nitrogen & Water & Protein & Lipid & Carbohydrate & $\mathrm{RS}$ & Ash \\
\hline & (kcal) & \multicolumn{8}{|c|}{$(\%, \mathrm{w} / \mathrm{w})$} \\
\hline Usukuchi & 55.0 & 15.8 & 1.00 & 70.1 & 5.7 & Trace & 8.0 & 4.11 & 16.2 \\
\hline Koikuchi & 67.0 & 13.9 & 1.34 & 68.6 & 7.6 & Trace & 9.1 & 4.10 & 14.7 \\
\hline Seasoning soup & 14.0 & 0.30 & 0.35 & 96.0 & 2.2 & Trace & 1.4 & 0.10 & 0.40 \\
\hline
\end{tabular}

Usukuchi and Koikuchi refer to light-colored and regular soy sauces, respectively.

$\mathrm{RS}$, reducing sugar. ${ }^{a)}$ The concentration of $\mathrm{NaCl}$ was determined by potentiometric titration method.

Table 2. Concentration of soy sauces and $\mathrm{NaCl}$ showing the highest scores from a sensory test.

\begin{tabular}{|c|c|c|c|c|}
\hline Sample & Soy sauce & Soy sauce $(\%, \mathrm{w} / \mathrm{w})$ & $\left.\mathrm{NaCl}-1^{a}\right)(\%, \mathrm{w} / \mathrm{w})$ & $\mathrm{NaCl}-2^{a)}(\%, \mathrm{w} / \mathrm{w})$ \\
\hline \multirow[t]{2}{*}{ Taro corm } & Usukuchi & 18.0 & 0.70 & 1.32 \\
\hline & Koikuchi & 18.0 & 0.86 & 1.41 \\
\hline \multirow[t]{2}{*}{ Potato tuber } & Usukuchi & 6.0 & 1.00 & - \\
\hline & Koikuchi & 6.0 & 0.94 & - \\
\hline \multirow[t]{2}{*}{ Pumpkin fruit } & Usukuchi & 6.0 & 0.30 & 1.50 \\
\hline & Koikuchi & 7.5 & 0.40 & 1.70 \\
\hline \multirow[t]{2}{*}{ Japanese radish root } & Usukuchi & 8.0 & 0.60 & 1.09 \\
\hline & Koikuchi & 10.0 & 0.76 & 1.25 \\
\hline \multirow[t]{2}{*}{ Carrot root } & Usukuchi & 12.0 & 0.54 & 0.80 \\
\hline & Koikuchi & 24.0 & 0.87 & 0.68 \\
\hline
\end{tabular}

$\mathrm{NaCl}-1$ and -2 are concentrations of $\mathrm{NaCl}$ in boiled sample and soup, respectively.

a) The concentration of $\mathrm{NaCl}$ was determined by silver nitrate titration method.

Table 3. Summary of cooking recipes using various ingredients $(\mathrm{g})$.

\begin{tabular}{|c|c|c|c|c|c|c|c|c|c|c|}
\hline \multirow{2}{*}{ Ingredient } & \multicolumn{2}{|c|}{ Taro corm } & \multicolumn{2}{|c|}{ Potato tuber } & \multicolumn{2}{|c|}{ Pumpkin fruit } & \multicolumn{2}{|c|}{ Japanese radish root } & \multicolumn{2}{|c|}{ Carrot root } \\
\hline & Usukuchi & Koikuchi & Usukuchi & Koikuchi & Usukuchi & Koikuchi & Usukuchi & Koikuchi & Usukuchi & Koikuchi \\
\hline Testing sample & 100.0 & 100.0 & 100.0 & 100.0 & 100.0 & 100.0 & 100.0 & 100.0 & 100.0 & 100.0 \\
\hline Usukuchi & 18.0 & 0 & 13.5 & 0 & 6.0 & 0 & 10.9 & 0 & 16.7 & 0 \\
\hline Koikuchi & 0 & 18.0 & 0 & 13.5 & 0 & 7.5 & 0 & 13.6 & 0 & 33.3 \\
\hline Seasoning soup ${ }^{a)}$ & 13.4 & 13.4 & 0 & 0 & 3.6 & 3.6 & 0 & 0 & 7.4 & 7.4 \\
\hline Distilled water & 186.7 & 186.7 & 90.0 & 90.0 & 54.4 & 52.9 & 0 & 0 & 103.7 & 103.7 \\
\hline Japanese sake ${ }^{b)}$ & 15.0 & 15.0 & 11.3 & 11.3 & 0 & 0 & 8.1 & 8.1 & 37.0 & 37.0 \\
\hline Sugar & 11.3 & 11.3 & 6.8 & 6.8 & 6.0 & 6.0 & 6.8 & 6.8 & 26.7 & 26.7 \\
\hline Salad oil ${ }^{c)}$ & 0 & 0 & 5.0 & 5.0 & 0 & 0 & 0 & 0 & 14.4 & 14.4 \\
\hline Mirin $^{d)}$ & 0 & 0 & 0 & 0 & 0 & 0 & 0 & 0 & 0 & 0 \\
\hline
\end{tabular}

${ }^{a)}$ White seasoning soup was prepared from shaved dried bonito.

${ }^{b)}$ The extract (carbohydrate and inorganic material), 5.6-6.0\% (w/v) and alcohol, 13-14\% (v/v).

c) Mixed with edible rapeseed and soybean oils.

${ }^{d)}$ Composed as follows: carbohydrate, $7.5 \mathrm{~g}$; protein, $0.02-0.09 \mathrm{~g}$ and sodium, $0.91 \mathrm{mg}$ in the $15 \mathrm{ml}$ of material. 
experiments were carried out at a constant room temperature of $25^{\circ} \mathrm{C}$, and the temperature of all materials before cooking was controlled at $25^{\circ} \mathrm{C}$. The size and shape of each sample were made as close as possible to the actual boiled foods in the daily diet according to the practical cooking method.

The cooking procedure for taro corm is shown in Fig. 1. The corm was cut in half across the longitude around the center with a knife. From one taro corm, one disc sample of $1 \mathrm{~cm}$ thickness was prepared. Thirteen taro samples obtained from 13 taro corms (total weight: ca. $200 \mathrm{~g}$ ) were used for the boiling experiment. At first, diluted seasoning soup (26.7 g) with distilled water of 373.3 g (total weight: $400 \mathrm{~g}$ ), Japanese sake ( $30 \mathrm{~g}$ ), soy sauce ( $36 \mathrm{~g}$ ) and sugar $(22.5 \mathrm{~g})$ were poured into the pan together, and boiled for $5 \mathrm{~min}$ by a heater $(1.4 \mathrm{~kW})$. The taro corm samples were placed in the pan with the stem-end side up and boiled in the soup containing Usukuchi or Koikuchi by a heater ( $260 \mathrm{~W})$ for 30 or $60 \mathrm{~min}$, respectively. After leaving them in the pan to soak for $60 \mathrm{~min}$, the firmness of the stem-end side of the taro discs was determined by rheological test.

For the potato tuber, one whole potato tuber ( $c a .100 \mathrm{~g}$ ) was cut across the longitude into 4 round slices of $1 \mathrm{~cm}$ thickness from the central portion between the stem-end and -top. The unnecessary outside portions of the round slice were cut out to adjust one disc to the same weight of $24 \mathrm{~g}$. For one experimental boiling, 10 potato discs ( $\mathrm{ca}$. $240 \mathrm{~g}$ ) obtained from 2-3 potato tubers were used in total. Thus prepared samples were placed in the pan with the tuber-end side up and added to pre-heated onion and meat in salad oil $(12.0 \mathrm{~g})$ in the pan and treated for $2 \mathrm{~min}$ by

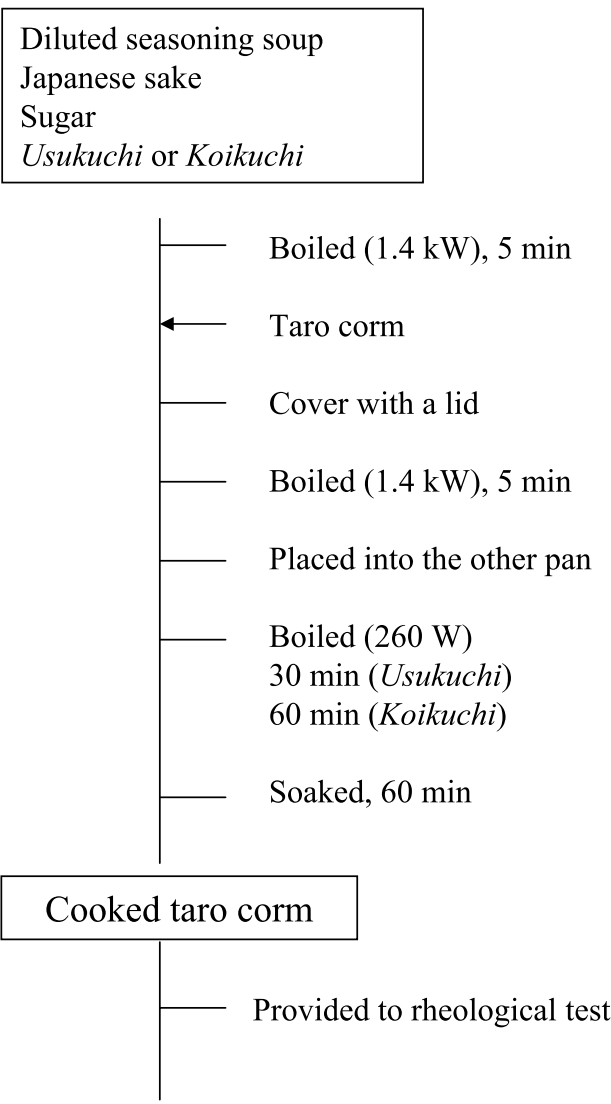

Fig. 1. Flow diagram of boiling for taro corm. heating $(900 \mathrm{~W})$, then distilled water $(216 \mathrm{~g})$ was added and heated for $5 \mathrm{~min}(450 \mathrm{~W})$. Subsequently, sugar (16.2 g), Japanese sake $(27 \mathrm{~g})$ and soy sauce $(32.4 \mathrm{~g})$ were added to these ingredients, covered with a lid and heated again for $20 \mathrm{~min}(450 \mathrm{~W})$, followed by additional heating uncovered for $3 \mathrm{~min}(700 \mathrm{~W})$. After heating for a specified time, the samples were cooled to room temperature for $10 \mathrm{~min}$, and the central portion of the tuber-end side was used for the rheological test. In addition, since one of the distinct differences between Usukuchi and Koikuchi is the $\mathrm{NaCl}$ concentration, the effects of both soy sauces on the boiling were tested by adjusting the concentration of $\mathrm{NaCl}: 0.5$, 1.0, 1.5 and $2.0 \%$ (w/w) using $\mathrm{NaCl}$ and distilled water. Usukuchi and Koikuchi contained 15.8 and $13.9 \%$ (w/w) of $\mathrm{NaCl}$, respectively. The potato disc samples prepared as described above were boiled with the following solutions: $\mathrm{NaCl}$ solution, Usukuchi and Koikuchi solutions added with the above 4 kinds of $\mathrm{NaCl}$ concentration at $700 \mathrm{~W}(10 \mathrm{~min})$ and $260 \mathrm{~W}(10 \mathrm{~min})$ using the same domestic electric cooker as described above.

A whole pumpkin was placed with the stem-end up and cut in half from the stem-end to blossom-end with a knife. One sample was cut into 4 slices from the stem-end to blossom-end again, and two cubic samples (W $3 \mathrm{~cm} \times \mathrm{D} 4 \mathrm{~cm} \times \mathrm{H} 3 \mathrm{~cm}$ ) were cut out from the central portion of each slice. Therefore, from one whole pumpkin fruit, 16 cubic samples were prepared. The placental side of the samples was placed up during boiling and treated according to the method reported by Tomioka et al. (2002). In brief, the samples $(c a .400 \mathrm{~g}$ ) were heated for $4 \mathrm{~min}$ at $1.4 \mathrm{~kW}$ in $232 \mathrm{~g}$ or $226 \mathrm{~g}$ of 15 -fold diluted seasoning soup. Then, sugar ( $24 \mathrm{~g}$ ) and soy sauce ( $24 \mathrm{~g}$ or $30 \mathrm{~g}$ ) were added to the ingredients, and heated for $7 \mathrm{~min}$ at $260 \mathrm{~W}$, followed by cooling to room temperature for $10 \mathrm{~min}$ to determine the firmness.

For Japanese radish root, the outer peel was peeled off, and cut in 4 discs from the central portion of the hypocotyl end with 2 $\mathrm{cm}$ thickness, and then the discs were cut into quarter circles. Therefore, 16 samples (ca. $280 \mathrm{~g}$ ) were prepared from one Japanese radish root in total. Boiling was carried out according to the same method as reported previously (Ikeuchi et al., 2002a). The radish samples were pre-boiled in distilled water $(500 \mathrm{~g})$ for 8 min at $900 \mathrm{~W}$ before cooking. Bonito-kelp soup (300 g) prepared beforehand, sugar (19 g) and Japanese sake (22.8 g) were mixed and boiled at $1.4 \mathrm{~kW}$. The pre-boiled radish samples and 4-5 thick blocks of deep-fried soybean curd $(100 \mathrm{~g})$ were added to the boiled soup and heated for $14 \mathrm{~min}$ at $260 \mathrm{~W}$, and soy sauce (30.4 g or $38 \mathrm{~g}$ ) was added and heated again for $1 \mathrm{~min}$ at $260 \mathrm{~W}$. Finally, the boiled radish was allowed to cool to room temperature for $20 \mathrm{~min}$ and used for the rheometry.

The carrot root was peeled and the portion of about $5 \mathrm{~cm}$ lengths from $2 \mathrm{~cm}$ inside the root-end was used. The carrot was then cut again into 5 discs of $1 \mathrm{~cm}$ thickness. The samples were cut into a flower shape with a stainless steel mold cutter. For one experimental boiling, 9 samples ( $c a .10 \mathrm{~g}$ each) obtained from two carrot root batches were used. The carrot samples were placed in the pan with the root-end side up, and cooked with other ingredients as chikuzen-ni stew, Japanese style stew by the same procedure as reported previously (Okuda et al., 2002b). Chicken $(125 \mathrm{~g})$ pre-heated in salad oil (13 g) for $2 \mathrm{~min}$ at 900 $\mathrm{W}$, commercial ingredient mixtures pre-boiled in water (lotus root, burdock, devil's tongue, bamboo shoot and shiitake mushroom, $450 \mathrm{~g}$ in total) and carrot samples ( $\mathrm{ca} .90 \mathrm{~g}$ ), which had 
Table 4. Firmness of boiled samples with soy sauces.

\begin{tabular}{lrr}
\hline \multirow{2}{*}{ Sample } & \multicolumn{2}{c}{ Firmness $^{a)}(\mathrm{N})$} \\
\cline { 2 - 3 } & Usukuchi & Koikuchi \\
\hline Taro corm & $4.59^{*} \pm 0.52$ & $6.09 \pm 0.52$ \\
Potato tuber & $3.27^{*} \pm 0.34$ & $4.05 \pm 0.32$ \\
Pumpkin fruit & $2.22 \pm 0.36$ & $2.35 \pm 0.40$ \\
Japanese radish root & $9.49^{*} \pm 0.26$ & $10.12 \pm 0.25$ \\
Carrot root & $6.22 \pm 0.53$ & $5.97 \pm 0.44$ \\
\hline
\end{tabular}

a) Firmness is maximum force value of after penetration of samples.

Values followed by the $*$ are significantly different from Koikuchi $(p<0.05)$. Data are average \pm standard deviation of 5 experiments.

been pre-boiled for $8 \mathrm{~min}$ at $1.4 \mathrm{~kW}$ were mixed and heated for 2 min at $900 \mathrm{~W}$. The seasoning solution containing Japanese sake (33.3 g) sugar ( $24 \mathrm{~g})$ and soy sauce ( $15 \mathrm{~g}$ or $30 \mathrm{~g}$ ) was then added to the ingredients and heated again for $10 \mathrm{~min}$ at $700 \mathrm{~W}$. After heating, the carrot samples were allowed to cool to room temperature for $20 \mathrm{~min}$ for rheological test. The central portion of the sample surface facing the root end was used for the penetration test.

All experimental boiling tests were repeated five times for the rheological test.

Rheological test of boiled foods The firmness of boiled foods was measured using a Fudoh rheometer (Rheotech Co., Ltd., Tokyo), as reported previously (Morita et al., 2002a; Morita et al., 2002b). The firmness was shown as the maximum force after penetration test of samples. The conditions of the rheometer were controlled as follows: the range, $20 \mathrm{~N}$; penetration speed, 6 $\mathrm{cm} / \mathrm{min}$; diameter of acrylic resin plunger with $5 \mathrm{~cm}$-height, 10 $\mathrm{mm}$. The penetration depth of plunger was controlled at $7 \mathrm{~mm}$ for taro, potato and carrot, and at $10 \mathrm{~mm}$ for Japanese radish and pumpkin. Before the measurement, the taro, potato and carrot were cut into $10 \mathrm{~mm}$ thickness. The thickness of other samples was as follows: Japanese radish, $20 \mathrm{~mm}$; pumpkin, $30 \mathrm{~mm}$.

Statistical analysis The results were statistically analyzed by $t$-test using SPSS (version 11.0; SPSS, Inc., Chicago, IL), and differences were considered significant at $p<0.05$.

\section{Results and Discussion}

Rheological property The firmness measurements were done in the central position of the various samples boiled with Usukuchi and Koikuchi using a rheometer (Table 4). The boiled taro was easily broken in the process of penetration of the plunger regardless of the kind of soy sauce, and the boiled taro with Usukuchi became significantly softer than that with Koikuchi. Though the cooking time for Koikuchi was 30 min longer than that for Usukuchi, the taro with Usukuchi was still soft. The taro treated with Usukuchi retained its natural color as compared with that with Koikuchi.

The Usukuchi softened the potato significantly compared to Koikuchi. As for cooking without other ingredients except for $\mathrm{NaCl}$ or soy sauce, the firmness of potatoes boiled in Usukuchi was lower than those in Koikuchi regardless of the $\mathrm{NaCl}$ concentration (Usukuchi, 2.05-2.75 N; Koikuchi, 2.92-3.25 N). Especially, at $1.5 \% \mathrm{NaCl}$, the potatoes with Usukuchi $(2.32 \mathrm{~N})$ were significantly softer than those with Koikuchi $(2.92 \mathrm{~N})$. However, the firmness of potatoes boiled in either sauce became harder with the increase of $\mathrm{NaCl}$ concentration tested, whereas the $\mathrm{NaCl}$ solution tended to soften it. Particularly, at the $2.0 \% \mathrm{NaCl}$ con- centration, potatoes treated with Koikuchi had the greatest firmness of all samples tested, and were significantly harder than those treated with the $\mathrm{NaCl}$ solution. Therefore, other factors except for the higher concentration of $\mathrm{NaCl}$ in Usukuchi than in Koikuchi might be related to softening of the structure of the boiled sample. For Japanese radish root, the sample boiled with Usukuchi was significantly softer than Koikuchi. In firmness for pumpkin fruit or carrot root, no significant differences in the hardness were observed; therefore, the effects of Usukuchi were assumed to be the same as those of Koikuchi from the rheological test.

Since soy sauces are popular and good seasonings, many studies have described the viewpoints of general analysis (Watanabe, 1990), recent trend of cooking (Chiba, 1988), antioxidative properties (Chiou et al., 2001; Esaki et al., 2002; Long et al., 2000) and cooking models (Odachi \& Oshiba, 1992; Ishizu, 1969; Ishizu, 1970; Shimomura \& Shimosaka, 1986). Nakatani et al. (1974a, 1974b) reported that $\mathrm{NaCl}$ in soy sauce softened soybean, whereas organic or amino acids hardened the structure. The authors propose that Usukuchi decreased the firmness of the boiled foods, such as taro corm, potato tuber and Japanese radish more than Koikuchi, and the present results seem consistent with those reported previously. This tendency was also correlated with the results of the sensory test that Usukuchi gave higher scores for boiled foods than Koikuchi as shown in Table 2. Therefore, the softness of boiled materials in Usukuchi might be one of the important factors affording the good taste or food texture of boiled foods.

These differences might be caused by the co-existence of organic acid (lactic acid or acetic acid), amino acid (pyroglutamic acid) in the soy sauce, or high molecular weight materials as browning products. The firmness of the penetrated position of the present samples measured by the rheometer was not necessarily the same as the firmness of other portions, because the firmness of vegetables was considered to differ depending on the penetration direction or region of the boiled material. In addition, components and characteristics of the broth of boiled vegetables, for example: amino acid, organic acid, carbohydrate, $\mathrm{pH}$, ion strength and osmotic pressure or heating conditions were considered to affect the rheological properties of the vegetables. Since the main constituents of cell wall of common vegetables are polysaccharides composed of cellulose and hemicellulose, and also the main inter-cellular substances are acidic heteropolysaccharides composed of pectin or protopectin, the structure or rheological properties of boiled materials were changed by the aggregation, solubilization, decomposition and polymerization of these substances.

Therefore, to obtain more information about suitable optimal use of soy sauce for boiling, studies on the effects of these components in soy sauce or broth, and heating conditions on rheological properties of boiled vegetables using Usukuchi or Koikuchi, as well as on the structure and digestibility of tissues of Usukuchi treated vegetables are to be pursued.

\section{References}

Belie, De. N., Laustsen, M.A., Martens, M., Bro, R. and Baerdemaeker, De. J. (2002). Use of physico-chemical methods for assessment of sensory changes in carrot texture and sweetness during cooking. J. Texture Stud., 33, 367-388. 
Chiba, H. (1988). Recent trend of the quality of soy sauce on the market. J. Brew. Soc. Jpn., 83, 678-680 (in Japanese).

Chiou, R. Y.-Y., Ku, K.-L., Lai, Y.-S. and Chang, L.-G. (2001). Antioxidative characteristics of oils in ground pork-fat patties cooked with soy sauce. J. Am. Oil Chem. Soc., 78, 7-11.

Esaki, H., Osawa, T. and Kawakishi, S. (2002). Potent antioxidative $o$ dihydroxyisoflavones in soy sauces and their antioxidative activities. Nippon Shokuhin Kagaku Kogaku Kaishi, 49, 476-483 (in Japanese).

Ikeuchi, M., Sawada, T., Yamada, K., Yamashita, H. and Yotsuya, M. (2002a). Seasonings of boiling for Japanese radish root and characteristics of light-colored soy sauce (Usukuchi). in: "Cooking Properties of Light-colored Soy Sauce (Usukuchi)," Higashimaru Co., Ltd., Hyogo, pp. 345-370 (in Japanese).

Ikeuchi, M., Sawada, T., Yamada, K. and Yotsuya, M. (2002b). Seasonings of boiled-cooking for potato tuber and characteristics of lightcolored soy sauce (Usukuchi). in: "Cooking Properties of Light-colored Soy Sauce (Usukuchi)," Higashimaru Co., Ltd., Hyogo, pp. 401-426 (in Japanese).

Ishizu, H. (1969). Flavor components of soy sauce. Chori Kagaku Kaishi, 2, 156-164 (in Japanese).

Ishizu, H. (1970). Heating and flavor components of soy sauce during cooking: Change of neutral substances. Chori Kagaku Kaishi, 3, 91-99 (in Japanese).

Long, L.H., Kwee, D.C.T. and Halliwell, B. (2000). The antioxidant activities of seasonings used in Asian cooking. Powerful antioxidant activity of dark soy sauce related using the ABTS assay. Free Fad. Res., 32, 181-186.

Morita, N., Maeda, T., Miyazaki, M., Yamamori, M., Miura, H. and Ohtsuka, I. (2002a). Dough and baking properties of high amylose and waxy wheat flours. Cereal Chem., 79, 491-495.

Morita, N., Maeda, T., Miyazaki, M., Yamamori, M., Miura, H. and Ohtsuka, I. (2002b). Effect of substitution of waxy-wheat flour for common flour on dough and baking properties. Food Sci. Technol. Res., 8, 119-124.

Nakatani, K., Matsumoto, F. and Sakurai, H. (1974a). The effects of soy-sauce (shoyu) on the texture of foodstuffs during the process of cooking (Part 1). Kaseigaku Zasshi, 25, 195-200 (in Japanese).

Nakatani, K., Matsumoto, F. and Sakurai, H. (1974b). The effects of soy-sauce (shoyu) on the texture of foodstuffs during the process of cooking (Part 2). Kaseigaku Zasshi, 25, 201-205 (in Japanese).

Odachi, J. and Oshiba, K. (1992). Sodium and potassium contents in pumpkins cooked with different kinds of soy sauce. Chori Kagaku Kaishi, 25, 228-232 (in Japanese).

Okuda, N., Masui, H. and Yokomizu, S. (2002a). Seasonings of boiling for taro corm and characteristics of light-colored soy sauce (Usukuchi). in: "Cooking Properties of Light-colored Soy Sauce (Usukuchi)," Higashimaru Co., Ltd., Hyogo, pp. 317-344 (in Japanese).

Okuda, N., Masui, H. and Yokomizo, S. (2002b). Seasonings of boiling for carrot of chikuzen-ni stew and characteristics of light-colored soy sauce (Usukuchi). in "Cooking Properties of Light-colored Soy Sauce (Usukuchi)," Higashimaru Co., Ltd., Hyogo, pp. 385-400 (in Japanese).

Shimomura, M. and Shimosaka, C. (1986). Effect of ginger juice added in soy sauce on hardness and protein profiles of cured sailfish meat. Chori Kagaku Kaishi, 19, 295-300 (in Japanese).

Tomioka, K., Nagatani, Y. and Mizuno, C. (2002). Seasonings of boiling for pumpkin fruit and characteristics of light-colored soy sauce (Usukuchi). in "Cooking Properties of Light-colored Soy Sauce (Usukuchi)," Higashimaru Co., Ltd., Hyogo, pp. 289-316 (in Japanese).

Ueda, K. (1977). Characteristics of light-colored soy sauce (Usukuchi). Chori Kagaku Kaishi, 10, 119-128 (in Japanese).

Watanabe, Y. (1990). Analysis of soy sauce with infrared multicomponent analyzer. Shoyu Kenkyu, 16, 40-42 (in Japanese). 